\title{
El fumus boni iuris y el periculum in mora en la tutela cautelar del contencioso administrativo chileno
}

\author{
Fumus boni iuris and periculum in mora as condition for \\ protective orders in the Chilean administrative process
}

Andrés Bordalí Salamanca*

El presente trabajo analiza de un modo general la tutela cautelar en el contencioso administrativo chileno. Su principal objetivo es mostrar cómo funcionan los presupuestos del fumus boni iuris y del periculum in mora, que tienen una operatividad diferente al proceso civil.

Palabras clave: Tutela cautelar, contencioso administrativo, fumus boni iuris, periculum in mora.
This paper analyses the temporary injunctions in the Chilean administrative justice. Its main objective is to show how do they work a danger budgets in delay and appearance of good right, that have a different operability to the civil process.

Keywords: Temporary injunctions, Administrative litigation, fumus boni iuris, periculum in mora.

\section{Introducción}

Frente a un actuar ilegal de la Administración, con ocasión de las potestades de regulación, fiscalización y sanción que tiene esta, los particulares afectados en sus derechos e intereses legítimos por dicha actuación pueden reclamar ante los tribunales de justicia, ejerciendo el derecho fundamental a la tutela judicial consagrado en la Constitución Política de la República de Chile (en adelante CPR) en los artículos 19 N³ inciso $1^{\circ}$ y 38 inciso $2^{\circ}$.

Sin embargo, el ejercicio en concreto de ese derecho a la tutela judicial para los administrados chilenos tendrá ciertas particularidades. En muchos casos, será un tribunal civil el que conocerá la pretensión de

\footnotetext{
* Abogado, Licenciado en derecho por la Universidad de Chile, Doctor en Derecho por la Universidad de Valladolid, España, Profesor Titular en la Facultad de Ciencias Jurídicas y Sociales de la Universidad Austral de Chile, Dirección Postal: Casilla 567, Valdivia, Región de Los Ríos, Chile. Correo electrónico: abordali@uach.cl

Recibido el 4 de noviembre de 2019 y aceptado el 10 de diciembre de 2019.
} 
esos sujetos, pues como sabemos no tenemos con un carácter general tribunales de lo contencioso administrativo. En algunos casos conocerán del referido contencioso algunos tribunales administrativos especiales. Esos tribunales, en algunas ocasiones, tramitarán la pretensión formulada por el actor de acuerdo a un proceso civil y todas las reglas comunes del juicio ordinario civil regulado en el Código de Procedimiento Civil (en adelante CPC). En algunas situaciones, esos tribunales de lo contencioso administrativo conocerán a través de un procedimiento especial, pero donde se aplicarán supletoriamente las reglas comunes y el juicio ordinario del Código de Procedimiento Civil.

Entre esas reglas aplicables supletoriamente, están aquellas referidas a las medidas precautorias como expresión de la tutela cautelar civil. Ello es así porque de conformidad con el artículo $3^{\circ} \mathrm{CPC}$, las reglas del juicio ordinario se aplican supletoriamente a todos aquellos procedimientos que no estén sometidos a una regla especial diversa, cualquiera sea su naturaleza.

De conformidad con lo señalado anteriormente, en aquellos contenciosos administrativos que no tengan una regulación especial aplicable en materia de medidas cautelares, se aplicarán las reglas de las medidas precautorias del Código de Procedimiento Civil.

Entre las medidas precautorias reguladas por el Código de Procedimiento Civil no está la suspensión del acto administrativo mientras se tramita el proceso, que es la medida cautelar básica y quizás mínima en todo contencioso administrativo. Sin embargo, el artículo 298 CPC autoriza al juez civil a decretar medidas atípicas o innominadas. Entre ellas podrá estar la suspensión del acto administrativo.

Señalado lo anterior, surge la duda si la regulación de las medidas precautorias del Código de Procedimiento Civil, con sus presupuestos y requisitos legales y de construcción doctrinal y jurisprudencial, se deben trasladar sin más a los procesos administrativos en que rigen supletoriamente. En concreto, es importante determinar si los presupuestos del fumus boni iuris y de periculum in mora, según su construcción procesal civil en nuestro derecho, pueden aplicarse al contencioso administrativo.

El presupuesto del fumus boni iuris aparece reconocido en el artículo 298 CPC. En efecto, señala el referido precepto que para decretar dichas medidas precautorias, "deberá el demandante acompañar comprobantes que constituyan a lo menos presunción grave del derecho que se reclama".

En relación al periculun in mora, es decir, el peligro jurídico derivado del retardo en la dictación de la sentencia definitiva que se pronuncia sobre la pretensión del actor, Este tiene diversas manifestaciones, de conformidad con los artículos 291 al 296 CPC. Consistirá por tanto, de conformidad con esos preceptos jurídicos, en "temor de pérdida de la cosa"; "temor de deterioro de la cosa"; "motivo racional para creer que [el demandado] procurará ocultar sus bienes; "temor que los derechos del demandante queden bur- 
lados" o bien, "que las facultades del demandado no ofrecieren suficiente garantía".

¿Se deben por tanto aplicar esos presupuestos al contencioso administrativo chileno? ¿Rige esta idea de una presunción grave del derecho que se reclama? ¿Se trata de los mismos peligros jurídicos antes indicados? Mi hipótesis de trabajo dirá que, por las particularidades del contencioso administrativo, esos presupuestos propios de la tutela cautelar civil deberán tener una comprensión diferente en el contencioso administrativo. Cuando se entienda que rige el presupuesto del fumus boni iuris, se deberá considerar, aunque sea superficial y provisoriamente, además de la situación jurídica cautelable del actor, la legalidad o no del acto administrativo. $Y$ respecto del periculum in mora, el que siempre deberá existir en toda medida cautelar, y para el caso que se lo considere como un perjuicio irreparable, se deberá considerar siempre aquellos perjuicios que no tengan una dimensión propiamente económica o resarcible.

Este trabajo no tiene por objetivo desarrollar una teoría general de la tutela cautelar en el contencioso administrativo, sino solo abordar dos de los aspectos probablemente menos tratados y considerados por la doctrina y jurisprudencia nacionales. Ellos son los presupuestos del fumus boni iuris y el periculum in mora en la tutela cautelar ante la justicia administrativa. Por ello, el trabajo no abordará un análisis de cuáles son las medidas cautelares que se pueden decretar en sede de contencioso administrativo; tampoco si debe exigirse caución o no para otorgarse una medida cautelar. Asimismo, no se abordarán las consideraciones que deben tenerse presente en torno al principio de proporcionalidad que debe regir en esta materia, como tampoco se analizará el procedimiento para dictar estas medidas. La mayor parte de esos aspectos ya han sido abordados en un trabajo anterior ${ }^{1}$.

\section{La tutela cautelar en el contencioso administrativo}

La posibilidad de adoptar medidas cautelares en el contencioso administrativo es un resorte que funciona como contrapartida a las prerrogativas que suele tener la Administración, referidas a la ejecutoriedad y ejecutividad de los actos de su propia producción ${ }^{2}$. Tales actos, en el derecho chileno, se presumen legales, y desde que están vigentes, la Administración de oficio puede ordenar su ejecución (art. $3^{\circ}$ inciso $8^{\circ}$ Ley $N^{\circ} 19.880$ sobre Bases de los procedimientos administrativos que rigen los actos de los órganos de la Administración del Estado).

En una apretada síntesis, se puede señalar que la ejecutoriedad del acto administrativo se refiere a que una vez que está vigente, este es obligatorio o vinculante para los destinatarios del acto $y$, desde luego, para la propia Administración. Pero además, una vez vigente el acto, la Administración puede

\footnotetext{
1 Bordali y Ferrada 2009, 187 y ss.

2 Moltó 2013, 81.
} 
ordenar su cumplimiento compulsivo, de oficio. Hablaremos en este caso de ejecutividad del acto o de autotutela ejecutiva.

Esta idea de la ejecutividad del acto administrativo no es compartida por toda la doctrina chilena, pues para autores como Eduardo Soto Kloss ${ }^{3}$, ello es algo enteramente excepcional, como en aquellos casos en que la ley expresamente ha previsto la creación de obligaciones de hacer que se imponen a los destinatarios, como sucede, por ejemplo, con las facultades que tiene Carabineros de Chile en materias de orden público. La regla general en el derecho chileno, para este sector de la doctrina, es la no ejecutividad del acto administrativo.

\section{El fumus boni iuris y el periculum in mora en el contencioso adminis- trativo comparado}

En el proceso civil, se acostumbra a entender que para que el juez pueda decretar una medida cautelar en beneficio del actor, debe existir una apariencia de que a su respecto existe un derecho de su titularidad ${ }^{4}$. No es un derecho enteramente declarado, lo que solo puede ocurrir con la sentencia definitiva, sino que es un derecho que, al comienzo del proceso, pareciera estar del lado de ese actor. Un derecho verosiblemente de titularidad del actor; una apariencia de derecho.

Hay varias situaciones que en un contencioso administrativo diferencian a este fumus boni iuris propiamente civil.

Desde luego, no siempre el actor tiene un derecho, sino que en muchas ocasiones se exige invocar un interés legítimo para poder accionar. En otros casos se concede una acción popular. De este modo, ya no se tiene siempre la figura del derecho subjetivo que existe mayoritariamente en el proceso civil.

Pero aún en la hipótesis de que quien demande invoque un derecho subjetivo, no siempre aparece claro que deba analizarse la apariencia de ese derecho para decretar la medida cautelar. O dicho de otra manera, no siempre el fumus boni iuris consiste en analizar si en cabeza del actor pareciera que existe un derecho, sino que muchas veces lo que hacen los tribunales del contencioso administrativo es analizar si la pretensión del actor tiene posibilidades de que prospere. En Europa, esta concepción del fumus boni iuris tiene sus orígenes en la jurisprudencia del Tribunal de Justicia de la Unión Europea 5 .

Esta distinta concepción del fumus boni iuris en el contencioso administrativo que en el proceso civil, sin duda está influenciada por la tradición del contencioso administrativo de tipo continental, en que se lo ha entendido como un proceso objetivo de control del acto administrativo y en que el actor normalmente tiene un interés legítimo más que un derecho subjetivo.

\footnotetext{
3 SOTO KLOSS 2017, 52 y 53.

4 Calamandrei 1996, 77.

5 JIMÉNEZ 2005, 180.
} 
De este modo, en algunas experiencias comparadas, como en el artículo 55 inciso $9^{\circ}$ del Código del Proceso Administrativo italiano, el fumus boni iuris consiste en una valoración sumaria sobre el mérito de la pretensión hecha valer por el ciudadano en su recurso.

En Italia, en el pasado, de acuerdo con diversas interpretaciones acogidas por la doctrina y por la jurisprudencia, el fumus boni iuris consistía básicamente en un juicio de probabilidad de estimación del recurso. En otros casos, se enjuiciaba si no existía una manifiesta falta de fundamentación del recurso.

Hoy en día, señala un sector de la doctrina italiana, en coherencia con lo expresado con la ley 205/2000, el actual Código del Proceso Administrativo parece acoger sin más la primera interpretación antes esbozada. Esto quiere decir que el juez concede una medida cautelar con base en una valoración sobre la razonable previsión sobre el resultado del recurso ${ }^{6}$. Esta opción por la primera tesis, no implica que la segunda haya decaído completamente, puesto que es bastante claro que si el recurso carece de una mínima fundamentación, la medida cautelar no será concedida ${ }^{7}$.

En España ha existido una larga polémica a nivel sobre todo jurisprudencial y en menor medida doctrinal, sobre si los presupuestos para decretar una medida cautelar en el contencioso administrativo debe basarse solo en el periculum in mora, o bien, también debe considerarse al presupuesto del fumus boni iuris.

Como destaca Moltó, los tribunales españoles han sido un tanto reacios a aceptar el fumus boni iuris en el primer sentido antes esbozado, pues de aceptarla, supondría avanzar la sentencia sobre el fondo o, dicho de otro modo, supondría darle la razón al actor de manera anticipada ${ }^{8}$.

Esta posición algo reacia hacia el fumus boni iuris como presupuesto para decretar una medida cautelar en el derecho español, tiene una justificación razonable, pues no tiene reconocimiento en la legislación de la jurisdicción contenciosa administrativa de dicho Estado. Solo desde el año 1998 pasó a tener recepción legal en la Ley de la Jurisdicción Contenciosa Administrativa para casos de inactividad y vías de hecho de la Administración. De ahí que la exigencia de este requisito, además del periculum in mora, no sea en absoluto una cuestión pacífica en la doctrina ni la jurisprudencia españolas?

De este modo, en España, para decretar una medida cautelar en favor del recurrente en el contencioso administrativo, normalmente suele exigirse solo la concurrencia del periculum in mora. En ocasiones excepcionales, además de ese peligro, se exige un fumus boni iuris.

\footnotetext{
6 Follieri 2014, 358; Casetta y Fracchia 2017, 216.

7 Travi 2016, 285.

8 Moltó 2013, 82.

9 Bueno y Rodríguez 2007, 241.
} 
Lo que está claro a este respecto en España, es que en la jurisprudencia del Tribunal Supremo, la exigencia del fumus boni iuris no ha tenido el respaldo suficiente para que, al día de hoy, pueda hablarse de un principio básico articulador del incidente. Su uso no está generalizado y su empleo pasa a ser residual ${ }^{10}$.

¿Por qué pese a no tener un expreso reconocimiento la exigencia del fumus boni iuris en la ley española, la jurisprudencia de los tribunales de lo contencioso administrativo a veces lo exige? Un sector de la doctrina señala dos tipos de justificaciones para ello.

En primer lugar, para alinearse con la jurisprudencia comunitaria, con especial mención del Tribunal de Justicia de las Comunidades Europeas (desde el caso Factortame). En segundo lugar, se lo ha utilizado, a juicio de Bueno y Rodríguez, para mejorar la situación de la tutela cautelar en el contencioso administrativo español en un doble sentido.

Así, en ocasiones se lo utiliza como un factor importante para dilucidar la prevalencia del interés que podría dar lugar a la procedencia de la suspensión del acto. En otros casos, minoritarios, el fumus boni iuris ha adquirido la consistencia necesaria para producir, por sí mismo y sin necesidad de un peligro claro, la adopción de la medida cautelar solicitada ${ }^{11}$.

Lo que queda en evidencia cuando se analiza la doctrina administrativista española con el tema de si debe exigirse el fumus boni iuris para otorgar una medida cautelar contra la Administración del Estado, ya sea conjuntamente con el periculum in mora o ya sea como único requisito exigible, es un posicionamiento de los autores, algo ideológico por lo demás, en torno a favorecer la posición del particular que litiga contra la Administración, o bien, para fortalecer la posición del fisco como representante del interés público.

Entre los que rechazan una posición referida a obtener una medida cautelar con base exclusiva en un fumus boni iuris, destaca Josep María Boquera, quien señala que de adoptarse tal criterio, se subvierte toda la arquitectura del Derecho Administrativo basado en la presunción de legalidad del acto administrativo. Asimismo, agrega, rompería la relación existente entre los poderes constituyente, legislativo y judicial, pues este último impone su impresión a la presunción de los primeros. "El mal humor reinante por el atraso en la resolución de los recursos contencioso-administrativos no debe aprovecharse para subvertir un principio fundamental del Derecho Administrativo"12.

En una línea similar, Carmen Chinchilla ha señalado que en España, la base determinante de las medidas cautelares es el periculum in mora. Sin este peligro, que debe frenarse para que el objeto del proceso se mantenga íntegro durante el tiempo que dure este, no podría hablarse de medidas cau-

10 JiMÉNEZ 2005, 178.

11 Bueno y Rodríguez 2007, 244.

12 Boquera 1994, 67. 
telares. Agrega que no se manifiesta contraria a la exigencia del fumus boni iuris, sino que rechaza su protagonismo exclusivo. "No conozco ni una sola resolución judicial que haya adoptado una medida cautelar, que verdaderamente sea tal, sobre la base exclusiva de la apariencia de buen derecho"13.

Por el contrario, existe una robusta doctrina que señala que el fumus boni iuris debe ser tenido en cuenta junto al periculum in mora o inclusive, por sobre este último o por si solo. Como ha señalado Eduardo García de Enterría, no se conoce ningún juez o tribunal que otorgue una suspensión cautelar, menos medidas cautelares positivas, por el simple argumento del daño irreparable, si simultáneamente no aprecia prima facie que el recurso pueda tener éxito en el fondo ${ }^{14}$.

Mariano Bacigalupo ha sostenido que solicitada una medida cautelar, se debe realizar una ponderación de los intereses concurrentes. Es decir, se debe proceder a realizar un examen sumario de las expectativas de estimación del recurso en el proceso principal. En definitiva, se debe examinar la legalidad de acto administrativo. Y todo ello debe realizar bajo la fórmula del fumus boni iuris ${ }^{15}$.

En el mismo sentido se expresa Bandrés Sánchez-Cruzat, cuando sostiene que el "juez contencioso-administrativo debe enjuiciar la procedencia de la pretensión cautelar, aplicando el criterio de apariencia de buen derecho (fumus boni iuris), realizando un examen "a primera vista" de la infracción o vicio de legalidad aducido contra el acto o disposición administrativa impugnados, sin prejuzgar la cuestión de fondo"16.

En este misma línea, en el libro de Carmen Jiménez, uno de los trabajos más profundos y especializados en esta materia del derecho español reciente, se señala que la tutela cautelar en el contencioso administrativo se debería dispensar no solo con base en la consideración de los daños, sino sobre la base de la solidez argumental de las pretensiones del recurrente, esto es, sobre el fumus boni iuris, cuya seriedad o entidad permitíra paralizar provisionalmente la actuación de la Administración ${ }^{17}$.

Algunos asocian directamente la aplicación de la doctrina del fumus boni iuris con el fortalecimiento de la posición del administrado, para así conseguir la necesaria tutela cautelar. En este caso se propicia una flexibilización del periculum in mora en caso de una especial cualificación del fumus boni iuris ${ }^{18}$.

13 Chinchilla 1993, 174.

14 García de Enterría 2000, 257.

15 Bacigalupo 1992, 434.

16 Bandrés Sánchez-Cruzat 2013, 102.

17 JIMÉNEZ 2005, 65.

18 Bueno y Rodríguez 2007, 245. 


\section{El fumus boni iuris y periculum in mora en el contencioso administra- tivo chileno}

En en caso chileno, al no tener un proceso contencioso administrativo general, sino algunas hipótesis de contenciosos administrativos especiales, ante jueces ordinarios o en algunos casos ante tribunales administrativos especiales, ello obliga a examinar caso a caso la situación de estos presupuestos de la tutela cautelar.

En aquellas situaciones en que se aplica supletoriamente las reglas del juicio ordinario y reglas comunes del Código de Procedimiento Civil, rige con claridad la exigencia de ambos presupuestos, esto es, el fumus boni iuris y el periculum in mora. Un caso de este tipo es el procedimiento de Nulidad de Derecho Público.

En otras ocasiones, la ley regulatoria de específicos contenciosos administrativos, exige expresa y únicamente el presupuesto del periculum in mora. En otras, este y además el fumus boni iuris.

Muy excepcionalmente en el derecho chileno, producto de la gravedad del daño que sufre el particular frente al acto administrativo, la ley prevé una suspensión automática del acto, por el solo hecho de presentar el recurso. Esto sucede en los casos de expulsión de extranjeros (artículo 89 Decreto ley $\left.N^{\circ} 1094\right)$ y de aplicación de una sanción grave a un operador del mercado financiero (artículo 46 del Decreto ley $\left.N^{0} 3.538\right)^{19}$.

Por último, está la situación del Recurso de Protección cuando mediante él se impugnan actos de la Administración del Estado. En este caso la Constitución no señala nada de cómo opera este mecanismo que en sí es considerado un procedimiento cautelar. Tampoco el Auto Acordado que regula el procedimiento de protección y que reconoce la orden de no innovar que se puede decretar dentro del procedimiento se refiere a los presupuestos del fumus boni iuris y periculum in mora.

\section{Situaciones en que la ley solo exige periculum in mora}

En algunas hipótesis del derecho chileno en que la ley ha regulado específicamente las medidas cautelares dentro de un proceso contencioso administrativo, el legislador, para que el juez pueda decretar una medida cautelar, solo exige el presupuesto del periculum in mora y no el fumus boni iuris.

Entre esos casos está la situación del a) Reclamo de llegalidad Municipal y el Reclamo de llegalidad Regional, así como también, b) los casos de impugnación de actos administrativos que vulneran los derechos fundamentales de los trabajadores.

a) En el caso de los reclamos de ilegalidad tanto municipal como regional, la ley dispone que el tribunal competente, esto es la Corte de Apelacio-

19 Ferrada y Sagredo 2015, 362. 
nes respectiva, podrá decretar orden de no innovar en la causa, cuando la ejecución del acto impugnado le produzca un daño irreparable al recurrente (artículos 151 e) Ley Orgánica Constitucional de Municipalidades y 108 e) de la Ley Orgánica Constitucional sobre Gobierno y Administración).

Esa orden de no innovar tiene por regla general un efecto suspensivo sobre los efectos del acto administrativo ${ }^{20}$. Con más precisión, Oelckers la define como "una medida cautelar consistente en suspender los efectos jurídicos propios del acto administrativo y que la determina el órgano jurisdiccional en prevención a que el necesario curso temporal del proceso pueda originar situaciones que hagan devenir en ineficaz, en la práctica, la resolución judicial que acoja la nulidad y deje sin efecto un acto administrativo, demanda deducida normalmente por el ciudadano afectado"21.

La escasa doctrina que se ha referido al concepto de daño irreparable para hacer procedente dictar una orden de no innovar, lo refiere a un daño que afecta valores no materiales, como podría ser la reputación de una persona, la conservación de un edificio histórico o artístico, la preservación de un paisaje o perspectiva de alto valor estético, la preservación del medio ambiente, entre otros ${ }^{22}$. Pero esa misma doctrina no descarta totalmente los daños patrimoniales, cuando su evaluación resulte tan difícil que impida llegar a una indemnización plenamente restitutoria, como podría ser en aquellos casos en se afecte la reputación o clientela de una empresa, o la fama de un producto.

Finalmente, en esta misma hipótesis de daños indemnizables, se incluyen aquellos casos en que se valora el tiempo de las personas como un activo limitado del que disponen. En esta situación se encontraría una decisión administrativa que restringe el derecho a estudiar, la que genera ruidos molestos o molestias graves, entre otros $\operatorname{casos}^{23}$.

b) En el caso del procedimiento judicial sobre tutela de los derechos fundamentales de los trabajadores, de conformidad con el artículo 492 del Código del Trabajo, el juez podrá ordenar la suspensión de los efectos del acto impugnado, cuando aparezca de los antecedentes acompañados al proceso que se trata de lesiones de especial gravedad o cuando la vulneración denunciada pueda causar efectos irreversibles.

No es tan evidente que ello opere de ese modo. De acuerdo con la legislación chilena, la situación puede ser todo lo contrario, pues el fumus boni iuris tradicionalmente requiere de medios de prueba que lo hagan verosímil, mientras en ninguna parte se exige comprobantes del daño o peligro.

\footnotetext{
20 Ibid. 353.

21 Oelckers 1995, 324.

22 Ibid, 328.

23 Ibid, 329.
} 
En un plano teórico, Gonzalo Cortéz señala que "cuando el legislador no subordina la adopción de una medida cautelar a la acreditación del peligro el peligro actuaría como fundamento; en tanto que si exige su alegación y prueba, estaría actuando a su vez como presupuesto" 24 .

Todo dependerá en definitiva de cómo el legislador haya previsto la concurrencia del peligro en la demora en la obtención de la medida cautelar. Si el legislador ha tipificado las circunstancias reveladoras del peligro, entonces el papel del juez se reduce a verificar la concurrencia o no de las mismas ${ }^{25}$. Si no hay tales circunstancias, entonces no procede tal verificación. Dicho de otro modo, en un caso se requerirá de la comprobación del peligro con algún medio de prueba y en el otro no será necesario.

En los casos del derecho chileno citados, para la obtención de la orden de no innovar o la medida de suspensión del acto administrativo, en principio el solicitante no debería acreditar con pruebas el peligro o daño que invoca, pues el legislador nada ha señalado.

Sin embargo, no escapa a la determinación de la existencia o no del peligro de daño, la propia dialéctica procesal. En efecto, si el demandado se opone a la medida cautelar, sosteniendo entre otras cosas, por ejemplo, que no existe el peligro que invoca, el solicitante de la medida se verá obligado a argumentar y probar, aunque sea tenuemente, que el peligro que él invoca existe.

Ahora bien, al no tener base legal la exigencia de prueba del daño o peligro, el juez tendrá una discrecionalidad bastante amplia para valorar este requisito. En todo caso, lo que no puede faltar de ningún modo, es una adecuada fundamentación de los presupuestos fácticos del daño o peligro de cargo de quien solicita la medida.

Entre las situaciones que deberá valorar el juez, está el determinar cuando un daño es irreparable o cuando los efectos son irreversibles, según las hipótesis del derecho chileno examinadas.

En el derecho comparado, particularmente en España, se ha dicho que se trata de daños o perjuicios que no tienen una naturaleza económica, de modo tal que no podrán ser justamente indemnizados. O bien, aun siendo indemnizables, su determinación pecuniaria presenta gran complejidad ${ }^{26}$.

En Italia se destaca algo similar. Así, en el reciente Código de Proceso Administrativo, la irreparabilidad del peligro ha sido entendida como una situación no susceptible de ser resarcida. Y, se agrega, debe tratarse de un peligro particularmente relevante, como la pérdida de un bien primario y no fungible y de imposible reparación ${ }^{27}$.

\footnotetext{
24 Cortéz 2017, 105.

25 Ibid, 106.

26 Ortells y Calderón 1996, 173.

27 Casetta y Fracchia 2017, 216.
} 
Con más detalle, Aldo Travi señala que el requisito de gravedad e irreparabilidad del perjuicio, según la jurisprudencia italiana, puede ser verificado en un sentido absoluto, es decir, en relación al tipo de intereses perjudicados por la providencia judicial, con independencia de las condiciones subjetivas del recurrente. De este modo, entre distintas hipótesis de perjuicio grave e irreparable, se destacan los casos que implican la destrucción de un bien, la cesación de una actividad, la pérdida de un puesto de trabajo, etcétera.

Pero también este requisito puede ser examinado de un modo relativo, tomando en consideración las condiciones subjetivas del recurrente, como sucede en la hipótesis de una sanción aplicada a él, cuyo monto sea exorbitante en relación a su renta ${ }^{28}$.

La ley italiana habla hoy en día de perjuicio y ya no de daño, lo que ha sido entendido por un sector de la doctrina en el sentido de no tener una cuantificación económica ${ }^{29}$.

Patricio Sammartino ha señalado que el daño irreparable queda configurado con la previsible imposibilidad de la sentencia de mérito de restablecer in natura la integridad del ejercicio del derecho lesionado. También habría daño irreparable en aquellos casos que si bien pudiera ser posible reparar o restablecer las cosas a la situación anterior, el mantenimiento de la ejecutividad del acto posee entidad suficiente para provocar las lesiones que, aun con el restablecimiento in natura del derecho al momento de dictarse sentencia, devendrían irreversibles ${ }^{30}$.

2. Situaciones en que el legislador exige copulativamente periculum in mora y fumus boni iuris

En otras situaciones de regulación legal de la tutela cautelar en el contencioso administrativo chileno, la ley contempla la clásica exigencia de las medidas cautelares del proceso civil, que tiene como presupuestos el periculum in mora y el fumus boni iuris. Entre estos casos se puede destacar a) el procedimiento judicial en la ley Antidiscriminación (Ley $N^{\circ} 20.609$ ); b) la tutela cautelar en la ley sobre Tribunales Ambientales (Ley $N^{\circ} 20.600$ ); c) la tutela cautelar en el procedimiento regulado en el D.L. N $N^{\circ} 211$ sobre protección de la libre competencia de los mercados y d) en la aplicación supletoria de las reglas sobre las medidas precautorias del Código de Procedimiento Civil, como podría ser una suspensión del acto administrativo en un proceso de Nulidad de Derecho Público o la medida de suspensión del procedimiento decretada por el Tribunal de Contratación Pública.

a) En el caso del procedimiento de la Ley Antidiscriminación, se exige, para suspender provisionalmente el acto reclamado, "además de la apariencia de buen derecho, su ejecución haga inútil la acción o muy gra-

\footnotetext{
28 TRAVI 2016, 286.

29 FolLIERI 2014, 357.

30 Sammartino 2004, 72 y 73.
} 
vosa o imposible la restitución de la situación a su estado anterior" (art. $7^{\circ}$ Ley $\mathrm{N}^{\circ}$ 20.609).

¿Qué se puede entender por apariencia de buen derecho en estos casos? Es poco el trabajo de nuestra doctrina y jurisprudencia sobre este aspecto Mirando la situación de nuestro entorno, en algunos casos, la jurisprudencia española ha señalado que no debe exigirse una nulidad de un acto de la Administración que sea ostensible y manifiesta, lo cual hace muy restrictiva la procedencia de la medida cautelar, sino que basta que el juzgador intuya que la actuación administrativa no está acorde con la legalidad o que la medida cautelar solicitada venga acompañada de una razón provisional con entidad suficiente como para frenar la eficacia inmediata de los actos, consecuencia de la presunción de validez del acto administrativo ${ }^{31}$.

Como se puede apreciar, la idea de apariencia de buen derecho en el contencioso administrativo avanza mucho más allá de la idea de que aparece verosímil que el actor es titular del derecho que reclama.

Cuando se atiende a la posición activa del recurrente, parece bien expresar la idea de un fumus boni iuris, aunque sea en un sentido muy amplio. Pero a veces se pone atención en la posición de la Administración, es decir, se valora si ha actuado ilegalmente, con lo que la apariencia ya no es de buen derecho sino de una actuación fuera de la ley (fumus mali acti).

Patricio Sammartino considera que cuando se analiza la apariencia de buen derecho en la tutela cautelar del contencioso administrativo, ello comporta un doble análisis conjuntivo: a) la verosimilitud del derecho del peticionario o fumus boni iuris, que debe invocar y demostrar, en grado de probabilidad o apariencia, en el sentido que es portador o beneficiario de una relación de disponibilidad o utilidad sobre bienes jurídicos en litigio, y b) la verosimilitud de la ilegitimidad del acto o fumus mali acti. En este caso el tribunal debe analizar si concurren o no indicios razonables de ilegitimidad susceptibles de autorizar, en el estadio procesal pertinente, la procedencia de la pretensión principal invocada ${ }^{32}$.

Como se decía, la doctrina chilena no ha reflexionado mucho sobre el sentido de la apariencia de buen derecho en el contencioso administrativo local. Los pocos trabajos en la materia señalan que "la tendencia en nuestro país, en los casos en que existe regulación legal, es facultar al tribunal para suspender el acto administrativo a solicitud del particular afectado, pero siempre que concurran ciertas circunstancias que así lo ameriten, especialmente los elementos clásicos del "humo de buen derecho" y "peligro en la demora" 33 .

31 Ibid, 90.

32 Sammartino 2004, 70 y 71.

33 Ferrada y Sagredo 2015, 362. 
Mauricio Viñuela habla de los pilares de la tutela cautelar en las cuestiones de naturaleza contencioso administrativas, entre los que destaca el fumus boni iuris y el periculum in mora. Y tratándose de medidas cautelares innominadas, agrega la necesidad de caución. Afirma este autor que la aplicación de estos criterios propios de la tutela cautelar civil al contencioso administrativo, resulta "a todas luces francamente insuficiente" 34 .

Un poco más allá avanza Osvaldo Oelckers cuando sostiene que en el contencioso administrativo, el fumus boni iuris o verosimilitud del derecho consiste en los indicios, circuntancias o antecedentes que rodean la pretensión principal, situaciones que dotan al acto administrativo de solo una apariencia probable de legitimidad que justifica que se tome la decisión de suspender los efectos del acto administrativo ${ }^{35}$.

Una verdadera excepción en nuestro medio es el caso de Alejandro Vergara, quien en sintonía con la doctrina española e italiana más autorizada y que se ha citado precedentemente, ha señalado que el fumus boni iuris en una medida cautelar del contencioso administrativo local equivale a sostener la probabilidad de éxito en el fondo de la cuestión ${ }^{36}$ planteada por un particular ante el tribunal del contencioso administrativo.

b) La tutela cautelar en la reclamación ante los Tribunales Ambientales. La Ley $\mathrm{N}^{\circ} 20.600$ sobre Tribunales Ambientales (en adelante LTA), en su artículo 24 y dentro a las reglas comunes a todo procedimiento, regula las medidas cautelares que se pueden decretar en los procesos tramitados ante dichos tribunales. La ley en este caso exige tanto fumus boni iuris como periculum in mora.

Señalado lo anterior, agregaré que en materia de medidas provisionales que puede decretar la Superintendencia del Medio Ambiente (artículo 48 Ley Orgánica Constitucional de la Superintedencia del medio Ambiente), que -según hemos sostenido con Iván Hunter ${ }^{37}$ - la jurisprudencia de los tribunales ambientales las considera como un tipo de medidas cautelares ${ }^{38}$, rigen tanto el fumus boni iuris como el periculun in mora.

Pero el legislador ambiental realiza un cambio a la clásica exigencia en esta materia, pues en el Código de Procedimiento Civil se exige fumus boni iuris referido al derecho que se reclama por el actor. En cambio, el artículo 24 LTA refiere a una verosimilitud de la pretensión invocada. Se puede sostener

\footnotetext{
34 VIÑUELA 2009, 1173.

35 Oelckers 1995, 326.

36 Vergara 2016, 370.

37 BORdali Y HUNTER 2017, 355.

38 Alejandro Romero Seguel es más enfático aún en relación a la naturaleza cautelar de las medidas provisionales que puede decretar la Superintendencia del Medio Ambiente. Señala que "[...] la ley 20.417 también faculta a la Superintendencia del Medio Ambiente, como órgano administrativo, para decretar medidas cautelares para asegurar el cumplimiento de la norma o instrumento de carácter ambiental, o evitar un daño inminente al medio ambiente o a la salud de las personas, entre las que se incluyen las medidas provisionales y urgentes". Romero Seguel 2013, 8.
} 
que la exigencia de verosimilitud referida a la pretensión y no al derecho ampliaría el marco donde se hace procedente una medida cautelar ${ }^{39}$.

Sin embargo, el inciso tercero del artículo 24 LTA vuelve al concepto clásico del fumus boni iuris, cuando expresa que "cuando se soliciten estas medidas, el requirente deberá acompañar los antecedentes que constituyan, a lo menos, presunción grave del derecho que se reclama o de los hechos denunciados". ¿Qué debe tener en consideración el Tribunal? ¿La verosimilitud de la pretensión o la existencia de una presunción grave del derecho que se reclama o de los hechos denunciados?

Pareciera que es más perentorio el inciso tercero, ya que el Tribunal debe examinar si existen antecedentes que constituyan a lo menos, presunción grave del derecho que se reclama o de los hechos denunciados.

Ahora bien, el concepto de verosimilitud de la pretensión utilizado en el inciso primero quizás únicamente tiene un fin práctico de sintetizar en una sola expresión introductoria, el concepto matriz que se refiere a la presunción grave del derecho reclamado o los hechos denunciados. Y lo anterior se hace necesario, pues no estamos frente a temas civiles, sino a aspectos administrativos, incluido el ámbito administrativo infraccional.

Por lo tanto, no parece haber una modificación por parte del legislador ambiental al clásico fumus boni iuris. Lo que ocurre es que ahora la situación es más amplia, pues se incorpora una hipótesis semejante a la que existe en materia penal del fumus comissi delicti, en este caso reemplazando el término delito por infracción administrativa. El térmimo verosimilitud de la pretensión abarcaría por tanto el fumus boni iuris (incluido el fumus mali acti) como el fumus comissi delicti administrativus.

Alguna jurisprudencia aprecia correctamente este sentido del humo de buen derecho. Cito un caso del Tercer Tribunal Ambiental, que ha entendido en parte la idea de apariencia de buen derecho en el sentido de fumus mali acti. Así, en su resolución de fecha 16 de noviembre de 2018, en la causa Rol $N^{\circ}$ R- 77-2018, el tribunal señaló:

"8. Que, respecto de la verosimilitud de la pretensión invocada (fumus boni iuris), es preciso discernir de forma preliminar sobre la verosimilitud de la hipótesis de ilegalidad de la resolución reclamada, y el riesgo asociado".

Tratándose de medidas provisionales, el Tercer Tribunal Ambiental ha valorado el fumus mali acti del siguiente modo en su sentencia de fecha 10 de diciembre de 2015, causa Rol S - 7- 2015:

"Sexto: Que (i) existiendo una conexión próxima entre las actividades materiales que se realizan para dar ejecución a la Resolución de Calificación Ambiental del proyecto "Construcción camino San Juan -Cabo Froward, tramo Río San Pedro- Punta Árbol, con presumible infracción a esta, y (ii) la

39 Un análisis similar al que se realiza acá ya consta en el trabajo de Bordalí 2019, 238 y ss. 
generación de riesgo constatada -que por la medida cautelar adoptada por este tribunal se encuentra contenida dicha generación-, con probabilidad de que (iii) se produzca un daño irreversible o de costosa recuperación a la especie Canquén Colorado [...]".

En el mismo caso, por sentencia de fecha 4 de noviembre de 2015, causa Rol S - 7- 2015, el tribunal había señalado:

"Vigésimo Sexto: [...] por lo que ejercerá de oficio la potestad cautelar del artículo 24 de la Ley $N^{\circ} 20.600$, y con el fin de resguardar un interés jurídicamente tutelado y teniendo en cuenta la verosimilitud de los hechos acaecidos y sus efectos, se procederá a decretar una medida cautelar innovativa según se indicará" (las cursivas son nuestras).

En este caso la verosimilitud es muy amplia, pues aparece referida a los hechos acaecidos y sus efectos, es decir, el supuesto fáctico normativo y su concreción en la realidad.

Expresado lo anterior, se debe mencionar además que existe una especial regulación referida al perjuicio o daño que se quiere conjurar con la medida cautelar. En efecto, el legislador ambiental regula expresamente las medidas cautelares innovativas, que buscan, por definición del legislador, modificar un estado de hecho o de derecho existente al tiempo de la solicitud de la medida (art. 24 LTA). Se trata de una medida algo más agresiva que la más clásica conservativa, pues alteran la situación jurídica o fáctica existente, lo que implica conceder de manera anticipada, aunque provisionalmente, la pretensión del actor.

Al ser la medida innovativa más agresiva que una de tipo conservativa, el legislador la reguló con un carácter excepcional o limitado. En efecto, el tribunal sólo podrá decretarla ante la inminencia de un perjuicio irreparable (art. 24 inciso $6^{\circ}$ LTA).

Hay varias cosas que precisar acá. Desde luego se debe aclarar qué es lo irreparable. Creo que ello se refiere tanto a cosas materiales como a derechos o intereses de las personas que reclaman. Evidentemente puede haber conexión entre unas y otras. Por ejemplo, si se autoriza un proyecto minero que implica tronaduras de una determinada zona o la construcción de una represa para un proyecto hidroeléctrico, que eliminará completamente o de un modo que no se pueda recuperar, un cementerio indígena, el daño es respecto al bien cementario que tiene un valor antropológico y, por tanto, de conformidad con el artículo $2^{\circ}$ LL) de la Ley $N^{\circ} 19.300$, también ambiental; pero de paso también podría implicar la vulneración del derecho fundamental a vivir en un medio ambiente libre de contaminación y, más seguramente, de un interés legítimo a vivir en una naturaleza preservada de personas vinculadas a la etnia a la que pertenece el referido cementerio.

Dicho lo anterior, hay que señalar que un sector de la doctrina sostiene que el peligro propio de la tutela cautelar es siempre irreparable, por lo que 
el art. 24 LTA no agregaría nada nuevo acá. Así, Gonzalo Cortéz, a propósito del periculum in mora en sede civil habla de "daño irreparable" ${ }^{40}$. Algunos autores restringen la idea de daño irreparable sólo al daño en la tardanza y no referido a la infructuosidad ${ }^{41}$. Otros agregan, como ya se ha visto, que la irreparabilidad del daño no se exige en aquellos casos de daños meramente económicos o cuando consista en una falta de satisfacer sumas de dinero ${ }^{42}$.

Como sea, la LTA solo exige ese daño inminente e irreparable tratándose de medidas innovativas. Tratándose de medidas conservativas, el peligro de daño no deberá reunir las características de inminencia e irreparabilidad. Se trataría de un peligro de daño menos exigente.

Un interesante caso judicial donde se relaciona el riesgo que puede producir una actividad humana con la producción de un daño irreparable al medio ambiente, se dio a propósito de la construcción de una carretera en la Región de Magallanes, donde se pidió una medida provisional por parte de la Superintendencia del Medio Ambiente al Tercer Tribunal Ambiental, con el fin de proteger una especie de ave endémica como lo es el Canquén Colorado. Por sentencia de 10 de diciembre de 2015, causa Rol No S - 7 - 2015, el referido tribunal señaló:

"Cuarto: generalmente se tiende a asumir que existe solo un concepto de riesgo, sin embargo esto no es así. La estructura del riesgo en un sistema dado puede tener dramáticos efectos en relación a qué tipo de acciones son aceptables y cuáles no. En el caso descrito en esta solicitud estamos ante un problema que puede ser: (i) de posible ruina o catástrofe para esta especie -que ya está en peligro de extinción-, donde el riesgo existente tiene probabilidades de causar daños irreparables, o (ii) de posible daño significativo, donde el riesgo existente también puede resultar en daños a esta especie, pero estos son recuperables a un altísimo costo".

Distingue esta sentencia entre daño irreparable y daño significativo. Parece ser que para este tribunal ambos tipos de daños pueden ser fundamento para una medida provisional o una cautelar innovativa.

Vemos de esta manera que deben acompañarse antecedentes. A diferencia del artículo 298 CPC en que se habla de comprobantes, podría entenderse que el legislador ambiental quiso ampliar la posibilidad de acreditación del derecho o de los hechos denunciados. Sin embargo, el inciso $5^{\circ}$ del mismo precepto restringe radicalmente la situación, pues expresa que en las controversias cautelares ambientales sólo se admite la prueba documental.

Interpretando ambos incisos, se llega a la conclusión que quien solicita la medida cautelar, debe acompañar documentos que acrediten su derecho, la ilegalidad de la actuación administrativa o los hechos denunciados.

40 Cortéz 2017, 101.

41 Ortells 2007, 937.

42 Casetta y Fracchia 2017, 215 
c) La tutela cautelar en el D.L. No211 sobre protección de la libre competencia en los mercados. Esta norma, en su artículo 25, se refiere explícitamente a que el Tribunal de Defensa de la Libre Competencia (TDLC) podrá dictar todas las medidas cautelares que sean necesarias para impedir los efectos negativos de las conductas sometidas a su conocimiento y para resguardar el interés común. A ese particular periculum in mora, el mismo precepto agrega que se deben acompañar antecedentes que constituyan a lo menos presunción grave del derecho que se reclama o de los hechos denunciados (fumus boni iuris y fumus comissi delicti administrativus). En este caso rigen supletoria y puntualmente algunas disposiciones sobre las medidas precautorias del Código de Procedimiento Civil (artículo 25 inciso final).

Destaca en esta normativa la referencia a medidas cautelares y ya no precautorias, denominación que se ha ido imponiendo en los distintos procedimientos judiciales chilenos desde la reforma procesal penal del año 2000.

En relación al periculum in mora, este se refiere a impedir los efectos negativos de las conductas sometidas al conocimiento del tribunal y para cautelar el interés común. "Aparece la idea del periculum in mora no solo referido al interés privado del solicitante, sino, también, una protección del interés común ligado a la libre competencia, sobre todo cuando el requirente es la FNE [Fiscalía Nacional Económica] ${ }^{43}$.

Ese interés común parece ser el interés público a la libre competencia en el mercado ${ }^{44}$, lo que no parece ser un fin en sí mismo, sino un medio para asegurar determinados resultados económicos y sociales ${ }^{45}$. En concordancia con lo aseverado, y como ha señalado el TDLC, en Chile y en el derecho comparado, la preocupación del derecho de la competencia no es proteger a determinados competidores, sino el proceso competitivo (Sentencia de fecha 30 de julio de 2014, Rol No 138-14).

Como sostienen Ortells y Bellido en España, los daños a aquél interés público concurrencial son irreparables con el medio de reparación consistente en la responsabilidad indemnizatoria, de ahí que el único camino adecuado sea el de impedir que esos daños se actualicen ${ }^{46}$. Esa es la vital importancia de las medidas cautelares en estos procedimientos. Esta explicación casi pedagógica de la tutela cautelar en el proceso sobre libre competencia la han ratificado los Ministros del TDLC María de la Luz Domper y Jaime Arancibia, quienes en un voto de minoría han señalado que "[...] cabe sostener que la suspensión de la licitación es el medio más idóeno y proporcionado de impedir los efectos negativos de las conductas aparentemente anticompetitivas y de resguardar el interés común, pues la mera reparación de los daños a las empresas excluídas por una licitación declarada eventualmente anticompeti-

\footnotetext{
43 Marín 2015, 609.

44 Arancibia 2017, 307.

45 PRAdo 2018, 244.

46 Ortells y Bellido 1999, 28.
} 
tiva en una sentencia definitiva, sugerida por el recurrente, solo permitiría indemnizar los daños al interés privado causados por tal atentado, impidiendo una adecuada satisfacción del interés público comprometido" (Sentencia de fecha 13 de marzo de 2018, Rol C - 341-2018).

En la jurisprudencia de nuestro TDLC, se ha entendido en un caso que al decretar una medida cautelar, con ello el tribunal entiende que está precaviendo eventuales riesgos de colusión, sin que precise si con ello está impidiendo los efectos negativos de las conductas denunciadas o se trata de resguardar el bien común. En este caso, si bien el tribunal no accedió a la petición de suspender una licitación por parte del Ministerio de Transportes y Telecomunicaciones para la operación de plantas de revisión técnica, sí estimó que la exigencia a cada proponente de presentar, a más tardar dos días hábiles administrativos antes de la entrega de las ofertas técnicas y económicas, una boleta de garantía en la que se señale la región a la que corresponde la licitación, la concesión específica a la que postula y el nombre del proponente, ello podría generar las condiciones de una eventual colusión entre los oferentes, por lo que ordenó cautelarmente al ministerio a modificar las bases de la licitación.

En el voto de minoría de la sentencia de dos Ministros del tribunal, se señala que la medida cautelar de modificación de las bases de licitación no debió ser decretada, al no estar acreditado el fumus boni iuris, ya que en el proceso no constaban antecedentes graves que permitan suponer que el número y procedencia de las referidas boletas de garantía podían ser conocidas por el resto de los proponentes, que era lo único que podía crear el riesgo detectado por la decisión de mayoría (Sentencia de fecha 30 de julio de 2014, Rol N C-256-13).

El fumus, como se puede apreciar en este caso, asume con claridad una idea de fumus comissi delicti administrativus.

d) Casos en que los presupuestos del fumus boni iuris y periculum in mora rigen por la aplicación supletoria de las reglas del Código de Procedimiento Civil. En algunos casos la ley no hace ninguna referencia a los presupuestos de la medida cautelar que puede adoptar el juez. Este es el caso de la medida cautelar de suspensión del procedimiento administrativo que puede decretar el Tribunal de Contratación Pública, según lo regulado por el artículo 25 de la Ley $N^{\circ} 19.886$ sobre Contratos de suministro y prestación de servicios. "El tribunal podrá decretar, por resolución fundada, la suspensión del procedimiento administrativo en el que recae la acción de impugnación".

La escasa doctrina que se ha referido al procedimiento que se tramita ante el Tribunal de Contratación Pública, sostiene que respecto a la medida cautelar de suspensión del procedimiento administrativo, debe estar informada por los presupuestos del periculum in mora y el fumus boni iuris o humo 
de buen derecho, que en este caso se entiende como probabilidad de éxito en el fondo de la cuestón deducida por el reclamante ante el tribunal ${ }^{47}$.

En sus ya catorce años de funcionamiento, el Tribunal de Contratación Pública se ha mostrado reacio a decretar la medida cautelar de suspensión de los procedimientos administrativos en que recae la reclamación formulada por los particulares. Por regla general rechaza la medida de suspensión que, junto al reclamo, suelen solicitar los particulares.

El tribunal suele decretar una resolución tipo para desechar la referida suspensión. Así, es común que resuelva de la siguiente manera: "Resolviendo la solicitud de suspensión del procedimiento licitatorio efectuada en el primer otrosí de la demanda de fojas 1 y siguientes: Atendido el mérito de los antecedentes hasta ahora reunidos, los cuales no producen en el tribunal la convicción necesaria como para decidir favorablemente la petición de suspensión solicitada, no ha lugar, sin perjuicio de lo que se resuelva en definitiva" (Sentencia de fecha 6 de diciembre de 2019, Rol N²61-2019).

En algunos casos el rechazo por parte del tribunal se debe a que el procedimiento administrativo donde debe incidir la suspensión, ya se encuentra terminado. En este caso, la medida cautelar pierde toda utilidad. Así, ha dicho el Tribunal que: "Teniendo únicamente presente que el procedimiento administrativo cuya suspensión se solicita se encuentra terminado por haberse dictado Resolución Adjudicatoria N²19 de fecha 17 de abril de 2009, y conforme, además, a lo previsto en los artículos 25 inciso $2^{\circ}$ de la Ley $N^{\circ} 19.886$, y 18 y 40 de la Ley $N^{\circ} 19.880$, no ha lugar a la suspensión solicitada" (Sentencia de fecha 26 de mayo de 2009, Rol N²3-2009).

Llama la atención que en los pocos casos en que el tribunal decreta la medida de suspensión del procedimiento administrativo, no fundamente mayormente por qué procede a decretarla. En general, suele señalar el Tribunal que atendido a los antecedentes del proceso y lo dispuesto en el artículo 25 de la Ley $N^{\circ} 19.886$, decreta la medida de suspensión, generalmente por 15 o 20 días. Así, en una resolución casi tipo señala: "Atendido el mérito de los antecedentes, lo dispuesto en el inciso segundo del artículo 25 de la ley $N^{\circ} 19.886$, ha lugar a la suspensión del procedimiento administrativo denominado Badofeno $10 \mathrm{mg}$ CM ID N 621-327-LR19, por un plazo de 15 días hábiles a contar de esta fecha, debiendo en consecuencia, la Central de Abastecimiento del Sistema Nacional de Servicios de Salud, abstenerse de ejecutar o celebrar cualquier acto administrativo o contrato, según sea el caso, dirigido a la prosecusión del proceso licitatorio previamente singularizado" (Sentencia de fecha 30 de agosto de 2019. Rol N²41-2019).

No suele argumentar mayormente el Tribunal de Contratación Pública con base a los presupuestos del fumus boni iuris y periculum in mora que

47 Vergara 2016, 370. 
tienen aplicación supletoria en este procedimiento en virtud del artículo $3^{\circ}$ del CPC.

\section{El caso especial del Recurso de Protección}

En la concepción mayoritaria de la doctrina y jurisprudencia nacionales, el Recurso de Protección es una acción o procedimiento cautelar ${ }^{48}$. Una vez iniciado el procedimiento de protección, la Corte de Apelaciones que conoce de él puede decretar como medida cautelar una orden de no innovar (art. $3^{\circ}$ inciso $5^{\circ}$ Auto Acordado sobre el Recurso de Protección). En el primer caso, es decir en el procedimiento de protección, estamos ante una hipótesis de tutela cautelar autónoma y en el segundo (orden de no innovar) en una clásica comprensión instrumental de la tutela cautelar, para asegurar el resultado de un proceso principal.

Las medidas cautelares autónomas y las propiamente instrumentales que puede decretar la Corte de Apelaciones en el Recurso de Protección no tienen presupuestos fijados en la Constitución ni en el Auto Acordado. Respecto de la orden de no innovar, el Auto Acordado se limita a señalar que ella puede ser decretada por el tribunal "cuando lo juzgue conveniente para los fines del recurso" (art. $\mathrm{N}^{\circ} 3$ inciso $5^{\circ}$ Auto Acordado). Respecto a la tutela cautelar principal que puede dictarse en el procedimiento de protección, se ha dicho que se le reconoció por la Constitución al tribunal de protección en términos muy amplios ${ }^{49}$. Ello por cuanto el artículo 20 CPR señala la Corte de Apelaciones competente "adoptará de inmediato las providencias que juzgue necesarias para restablecer el imperio del derecho y asegurar la debida protección del afectado". Como se ve, la Constitución confiere plena discrecionalidad a la Corte de Apelaciones que conoce de la pretensión de protección para dictar la medida que estime oportuna, sin que restrinja esa facultada algún presupuesto o requisito ${ }^{50}$.

Ahora bien, como esa inexistencia de presupuestos normativos para dictar las medidas cautelares, ya seas las autónomas o las instrumentales, produce una cierta inseguridad jurídica y un amplio despliegue de la discrecionalidad judicial, las Cortes de Apelaciones han ido delineando algunos requisitos para su dictación. Esos requisitos son los del derecho indiscutido y asunto debatido no complejo.

En efecto, de acuerdo con la jurisprudencia de las Cortes, para decretar una medida cautelar autónoma o una orden de no innovar, el derecho tiene que ser indiscutido. Es decir, el Recurso de Protección como procedimiento cautelar no puede dar tutela a un derecho en la medida que este sea discutido o incierto; tampoco cuando el asunto sea complejo.

\footnotetext{
48 Un análisis de la doctrina y jurisprudencia sobre la concepción del Recurso de Protección puede verse en BORDALI 2019, 149 y ss.

49 VIÑUELA 2009, 1171.

50 Oelckers 1995, 324.
} 
Así, las Cortes han construido un término semejante al fumus boni iuris, propio de la tradicional cautela civil, que se lo denomina existencia de un derecho indubitado o indiscutido.

Este término requiere de ciertas precisiones ${ }^{51}$. En primer lugar, si se trata de derechos fundamentales, estos en esencia son indiscutidos o indubitados. A diferencia de los derechos subjetivos privados que surgen de la autonomía privada mediante actos negociales como contratos, donaciones, testamentos, o bien de sentencias y de decisiones administrativas, los derechos fundamentales tienen su título y origen inmediatamente en la ley, esto es, son conferidos a través de reglas jurídicas, de rango habitualmente constitucional.

Esto quiere decir que lo discutido no puede versar sobre el derecho fundamental mismo, pues éste es inherente a la persona humana. Lo que sucede es que el Recurso de Protección se utiliza en muchas ocasiones para derechos que pueden ser considerados más como derechos patrimoniales que derechos fundamentales, como sucede con la propiedad, sin perjuicio de que en nuestra dogmática constitucional no exista duda alguna que la propiedad es un derecho fundamental.

Esta es la situación que hace un tiempo falló la Corte de Apelaciones de Concepción por sentencia de 23 de octubre de 2014, rol, 3311-2014, que fue confirmada posteriormente por la Corte Suprema. Sostuvo la Corte de Concepción en Recurso de Protección interpuesto por usuarios o consumidores de gas ciudad contra la empresa Gas Sur S.A., en un tema básicamente referido a tarifas, lo siguiente:

$7^{\circ}$. "Que de lo expuesto aparece que la recurrente no ha demostrado en estos autos ser titular de un derecho indiscutido y preexistente de aquellos cuyo imperio esta Corte debe proteger por mandato constitucional. El Recurso no es la vía para declarar, constituir o extinguir derechos y solo opera cuando los derechos amagados son indiscutidos".

Los recurrentes en este caso invocaron la afectación del derecho a la igualdad ante la ley y el derecho de propiedad. Este último derecho fundamental tiene la estructura de un derecho patrimonial y, como tal, no consta a priori su existencia la que debe ser demostrada.

Un poco antes, el Tribunal Constitucional, por sentencia de 9 de septiembre de 2014, Rol 2538-14, había sostenido algo semejante:

"[...] su naturaleza jurídica [la del Recurso de Protección] es la de una acción cautelar, para la defensa de derechos subjetivos concretos, que no es idónea para declarar derechos controvertidos, sino tan solo para restablecer el imperio del derecho y asegurar la debida protección del afectado, en presencia de una acción u omisión arbitraria o ilegal, que amerita una solución urgente".

51 Este análisis puede ser visto en BORDALl 2019, 169 y ss. 
Pero tratándose de derechos no patrimoniales, como el derecho a la vida, a vivir en un medio ambiente libre de contaminación, entre otros, lo indubitado no puede ser referido al derecho, que todas las personas que habitan este país por mandato constitucional tienen y pueden gozar de él, sino que lo indubitado estará referido a si el derecho ha sido vulnerado o no, por acciones u omisiones imputables a otro sujeto.

Esto quiere decir que en el procedimiento de protección, para que se proceda a decretar medidas de protección, debe ser indiscutido que el derecho fundamental de un sujeto ha sido privado, perturbado, amenazado o afectado, mediante acciones u omisiones arbitrarias o ilegales, y que por lo demás exista una necesidad manifiesta y urgente de tutela jurisdiccional.

Así lo ha reconocido la Corte de Apelaciones de Temuco por sentencia de 16 de octubre de 2014, rol 2355-14, la que ha sostenido que:

"4. Es indispensable que quien lo intente [el Recurso de Protección] acredite la existencia de un derecho actual que lo favorezca, que esté claramente establecido y determinado [...]".

$5^{\circ}$ "[...] para que el recurso de protección sea acogido, es necesario que los hechos en que se hace consistir la arbitrariedad o ilegalidad, estén comprobados y que con estos hechos se haya sufrido perturbación, privación o amenaza en el ejercicio legítimo de las garantías y derechos que la Constitución asegura y que son los enumerados taxativamente en el artículo 20 de este cuerpo legal".

Como se trata de un procedimiento cautelar sin contradictorio ni período de prueba, el procedimiento de protección tampoco es la sede para resolver asuntos complejos. Un buen ejemplo de esto son los temas ambientales. Los conflictos ambientales cada día más constituyen un intrincado complejo de derechos e intereses contrapuestos entre empresas, ciudadanos, comunidades indígenas y la Administración del Estado. La jurisprudencia se ha ido inclinando por la tesis de que estos conflictos no pueden ser conocidos vía Recurso de Protección. Esto lo ha sostenido la Excelentísima Corte Suprema por sentencia de fecha 29 de abril de 2014 en los autos rol 2892-2014. En este caso, los recurrentes de protección alegaban que un determinado proyecto generaba los efectos señalados en el artículo 11 de la ley 19.300 y por tanto la evaluación del proyecto debió haberse realizado por un Estudio de Impacto Ambiental y no por una Declaración de Impacto Ambiental. La Corte Suprema señaló:

Sexto: "Que dicho lo anterior, esta Corte estima necesario dejar anotado que lo pretendido a través de esta acción cautelar es que se analice la validez de un acto administrativo ambiental terminal y ejecutoriado, que como tal goza de presunción de legalidad según lo reconoce la Ley $N^{\circ} 19.880$, arguyéndose que un determinado proyecto debió ser examinado mediante un Estudio de Impacto Ambiental y no por una Declaración de Impacto Ambiental. 
Como es posible inferir, determinar si es procedente uno u otro mecanismo de evaluación ambiental luego de que ya la autoridad administrativa con competencia técnica resolvió aprobar y, por ende, otorgar el permiso ambiental a través de una Declaración de Impacto Ambiental, corresponde a una cuestión en extremo compleja que, por regla general, va a exceder el ámbito propio de esta acción constitucional.

En efecto, decidir si se producen los efectos previstos en el artículo 11 de la Ley de Bases del Medio Ambiente luego de que las autoridades ambientales ponderaron y resolvieron en la materia exige apreciar proyectos o actividades sobre la base de evaluaciones técnicas, labor que en principio resulta ajena a este procedimiento cautelar.

Séptimo: Que si bien la jurisprudencia de esta Corte ha validado un intenso control sustantivo de las resoluciones de calificación ambiental, no restringiéndose únicamente a aquellos casos en que éstas habían incurrido en una manifiesta ilegalidad -ocasión en que evidentemente es procedente la acción de protección- no es posible obviar que ello pudo justificarse hasta antes de que nuestro ordenamiento jurídico a través de la Ley $N^{\circ} 20.600$ de 2012 creara los tribunales ambientales, pues desde que estos se instalaron y ejercen su jurisdicción constituyen la sede natural para discutir este asunto dados los términos en que se ha planteado".

\section{Conclusiones}

1. Al no existir en Chile un régimen unitario de contencioso administrativo, ello repercute en un régimen variable de la tutela cautelar en los diversos contenciosos administrativos que existen.

2. La medida cautelar por excelencia de los contenciosos administrativos chilenos es la suspensión del acto administrativo. Por disposición de la ley, a veces funciona como suspensión de los efectos del acto administrativo, pero en otras ocasiones adopta la fisonomía de una orden de no innovar con efectos suspensivos.

3. Los presupuestos de la tutela cautelar en sede de contencioso administrativo no son los mismos que en sede procesal civil. En la justicia civil se exige siempre fumus boni iuris y periculum in mora. En cambio, en materia de contencioso administrativo, a veces solo se exige un periculum in mora (Reclamo de ilegalidad municipal y regional; procedimiento de tutela laboral del Código del Trabajo). En los demás casos se exige por disposición directa de la ley o por aplicación supletoria del Código de Procedimiento civil, ambos presupuestos, como en sede civil, aunque con una diversa intelección.

4. Cuando en el contencioso administrativo se entiende que rige el presupuesto de la apariencia de buen derecho, se deberá considerar, aunque sea superficial y provisoriamente, la situación jurídica cautelable del actor, esto es, si es verosímil que es titular de un derecho subjetivo o de un interés legítimo (fumus boni iuris). Pero también, se debe realizar un análisis sobre la 
apariencia de ilegalidad del acto administrativo (fumus mali acti). Y respecto del periculum in mora, el que siempre deberá existir en toda medida cautelar, se deberá considerar siempre aquellos perjuicios que no tengan una dimensión propiamente económica o que pueda traducirse en una indemnización de perjuicios.

5. En aquellos contenciosos administrativos donde se exige exclusivamente un presupuesto de periculum in mora y no de fumus boni iuris, la carga para el solicitante de la medida solo consistirá en argumentar sobre la posibilidad de un daño irreparable (periculum in mora) si se mantienen los efectos del acto administrativo. En los casos examinados en este trabajo, la ley no exige comprobar de ningún modo la existencia de ese daño. Sin embargo, si el sujeto pasivo de la medida cautelar la impugna, el solicitante de la misma, por exigencias propias de la dialéctica del proceso, además de argumentar, se verá sujeto a la carga de acompañar comprobantes que justifiquen, aunque someramente, la posibilidad de ese daño.

6. En el Recurso de Protección, para que la Corte de Apelaciones pueda decretar una orden de no innovar o ya la medida cautelar autónoma, tendrá que tratarse de una situación fáctica referida al derecho fundamental necesitado de amparo, de carácter indiscutida. Asimismo, la medida a decretar no podrá recaer en un asunto complejo que necesite un proceso judicial con todas las garantías.

\section{Bibliografía Citada}

AranciBIA, Jaime (2017). Control de actos licitatorios ante el Tribunal de la Libre Competencia. Revista de Derecho, Valdivia, Vol XXX - N², pp. 301-316.

BACIGALUPO, Mariano (1992). El sistema de tutela cautelar en el contencioso-administrativo alemán tras la reforma de 1991. Revista de Administración Pública, N 128, mayo-agosto, pp. 413-452.

Bandrés SÁnchez-Cruzat, José Manuel (2013). Los desafíos de la justicia contencioso -administrativa del siglo XXI. Valencia, Tirant lo Blanch, 351 pp.

Boquera, Josep María (1994). Insusceptibilidad de la suspensión de la eficacia del acto administrativo. Revista de Administración Pública, № 135, septiembre-diciembre, pp. 37-76.

Bordall, Andrés (2019). Litigación ambiental. Santiago de Chile, Thomson Reuters, 275 pp.

Bordali, Andrés y Ferrada, Juan Carlos (2009). Estudios de Justicia Administrativa. Santiago de Chile, Legal Publishing, 233 pp.

Bordalí, Andrés y Hunter, Iván (2017). Contencioso administrativo ambiental. Santiago de Chile, Librotecnia, 408 pp.

Bueno, Antonio y Rodríguez, Manuel Antonio (2007). El fumus boni iuris como criterio contrario al solicitante de medidas cautelares. ¿Un traidor entre los aliados?. Revista de Administración Pública, N 172, enero-abril, pp. 227-253.

Calamandrel, Piero (1996). Introducción al estudio sistemático de las providencias cautelares. Buenos Aires, Librería El Foro, 232 pp.

Casetta, Elio y Fracchia, Fabrizio (2017). Giustizia Amministrativa. Turín, Giuffrè, 392 pp.

ChInCHILla, Carmen (1993). El derecho a la tutela cautelar como garantía de la efectividad de las resoluciones judiciales. Revista de Administración Pública, N 131, mayo-agosto, pp. $165-190$.

Cortéz, Gonzalo (2017). La tutela cautelar en el proceso civil, Santiago de Chile, Thomson Reuters, $474 \mathrm{pp}$. 
Ferrada, Juan Carlos y SAgredo, Pablo (2015). La tutela cautelar en la justicia administrativa chilena: fundamentos, regulación, limitaciones y desafíos. Revista de Derecho, XLIV, primer semestre, Valparaíso, pp. 337-367.

Folılerl, Enrico (2014). La fase cautelare. Giustizia Amministrativa, Scoca, Franco Gaetano (editor), Turín, Giappichelli, pp. 342-370.

García de Enterría, Eduardo (2000). Observaciones sobre la tutela cautelar en la nueva Ley de la Jurisdicción Contencioso-Administrativa de 1998. ¿Tienen efectiva potestad de acordar tutela cautelar las Salas de los Tribunales Superiores de Justicia y de la Audiencia Nacional. Revista de Administración Pública, N 151, enero-abril, pp. 251-280.

JIMÉNEZ, Carmen (2005). El fumus boni iuris: un análisis jurisprudencial, Madrid, lustel, 248 pp.

MARín, Juan Carlos (2015). Tratado de las medidas cautelares. Doctrina, jurisprudencia, antecedentes históricos y derecho comparado. Santiago, Editorial Jurídica de Chile, 680 pp.

Moltó, José María (2013). Litigación administrativa. Barcelona, Bosch, 281 pp.

Nivarra, Luca, Ricciuto, Vincenzo y Sconamiglio, Claudio (2016). Istituzioni di Diritto Privato, Turín, Giappichelli, 553 pp.

OelCKers, Osvaldo (1995). La suspensión de los efectos del acto administrativo debido a la orden de no innovar. Revista de Derecho de la Universidad Católica de Valparaíso, XVI, pp. 323-331.

OrTelLS, Manuel (2007). Derecho procesal civil, séptima edición, Navarra, Thomson Aranzadi, $1114 \mathrm{pp}$.

Ortells, Manuel y Calderón, María Pía (1996). La tutela judicial cautelar en el derecho español, Granada, Comares, 187 pp.

Ortells, Manuel y BeLLIDO, Rafael (1999). Las medidas cautelares en derecho de la competencia. Valencia, Tirant lo Blanch, 175 pp.

Prado, Gabriela (2018). Comentario a la sentencia Rol № 47. 555/2016 de la Corte Suprema, de 4 de octubre de 2017, Empresa WSP Servicios Postales S.A. con Superintendencia de Salud. Revista de Derecho № 51, segundo semestre, Valparaíso, pp. 233-246.

Quezada, José (1988). Medidas prejudiciales y precautorias. Santiago de Chile, Editorial Ediar-Conosur, $272 \mathrm{pp}$.

Romero Seguel, Alejandro (2013). Informe en Derecho: Distinción entre el sistema cautelar administrativo y jurisdiccional. Disponible en: tribunalambiental.cl/wp-content/ uploads/2014/07/R-07-2013-Informe - en - derecho - de - dpn - Alejandro - Romero - Seguel1. Pdf.

Sammartino, Patricio (2004). Medidas cautelares frente a autoridades públicas. Documentación Administrativa, № 269-270, mayo-diciembre, pp. 55-87.

Sото KLoss, Eduardo (2017). La aplicación del acto administrativo. lus Publicum, Nº 39, pp. 41-53.

Travl, Aldo (2016). Lezioni di Giustizia Amministrativa, Turín, Giappichelli, 401 pp.

VALDIVIA, José Miguel (2015). Contenido y efectos de las sentencias de los tribunales ambientales. En: La nueva justicia ambiental, Ferrada, Juan Carlos, et al., Santiago de Chile, Thomson Reuters, pp. 253-276.

Vergara, Alejandro (2011). Esquema del contencioso administrativo: su tendencia hacia un modelo mixto y situación actual del Recurso de Protección. En: Litigación Pública, Arancibia, Jaime, et al., Santiago de Chile, Abeledo Perrot Thomson Reuters, pp. 37-63.

Vergara, Alejandro (2016). Tribunal de Contratación Pública: bases institucionales, organización, competencia y procedimiento. Revista de Derecho (Valparaíso), XLVI, primer semestre, pp. 347-378.

VIÑUELA, Mauricio (2009). La tutela cautelar de derechos ante la Administración: la realidad chilena. En La primacía de la persona. Estudios en homenaje al profesor Eduardo Soto Kloss, Arancibia, Jaime y Martínez, José Ignacio (coordinadores), Santiago de Chile, Legal Publising, pp. 1159-1178.

\section{Normativa citada}

Auto Acordado sobre tramitación del Recurso de Protección. 
Código de Procedimiento Civil.

Código del Proceso Administrativo italiano.

Ley N ${ }^{\circ}$ 18.695, Ley Orgánica Constitucional de Municipalidades. Diario Oficial, 26 de julio de 2006.

Ley No 19.175, Ley Orgánica Constitucional sobre Gobierno y Administración Regional. Diario Oficial, 8 de noviembre de 2005.

Ley $\mathrm{N}^{\circ} 19.880$, que Establece bases de los procedimientos administrativos que rigen los actos de los órganos de la Administración del Estado. Diario Oficial, 29 de mayo de 2003.

Ley $N^{\circ} 19.886$, Bases sobre contratos administrativos de suministro y prestación de servicios. Diario Oficial, 30 de julio de 2003.

Ley N $\mathrm{N}^{\circ}$ 20.600, Crea los Tribunales Ambientales. Diario Oficial, 28 de junio de 2012.

Ley $N^{\circ} 20.609$, Establece medidas contra la discriminación. Diario Oficial, 24 de julio de 2012.

Decreto Ley $N^{\circ} 211$, Establece normas sobre libre competencia en los mercados.

Decreto Ley $N^{\circ}$ 1.094, Establece normas sobre extranjeros en Chile. Diario Oficial, 19 de julio de 1975.

Decreto Ley No 3.538, Crea la Comisión para el Mercado Financiero. Diario Oficial, 23 de diciembre de 1980.

\section{Jurisprudencia citada}

Solicitud Superintendencia del Medio Ambiente (2015): Tercer Tribunal Ambiental, 10 de diciembre de 2015.

Solicitud Superintendencia del Medio Ambiente (2015): Tercer Tribunal Ambiental, 4 de noviembre de 2015.

Simonetti con Servicio de Evaluación Ambiental (2018): Tercer Tribunal Ambiental, 11 de noviembre de 2018.

Ramírez con Ministerio de Transportes y Telecomunicaciones (2014): Tribunal de Defensa de la Libre Comptencia, 30 de julio de 2014 (acumulada).

Ramírez con Ministerio de Transportes y Telecomunicaciones (2014): Tribunal de Defensa de la Libre Competencia, 30 de julio de 2014.

Transaber con Ministerio de Transportes y Telecomunicaciones (2018): Tribunal de Defensa de la Libre Competencia, 13 de marzo de 2018.

Vertex con Secretaría Regional Ministerial de Bienes Nacionales de la Región de Coquimbo (2009): Tribunal de Contratación Pública, 26 de mayo de 2009.

Pharmamerica con CENABAST (2019): Tribunal de Contratación Pública, 30 de agosto de 2019.

Sur Social Consultora con SERVIU VI Región (2019): Tribunal de Contratación Pública, 6 de diciembre de 2019.

Corte Suprema (2014): 29 de abril de 2014.

Corte de Apelaciones de Concepción (2014): 23 de octubre de 2014.

Tribunal Constitucional (2014): 9 de septiembre de 2014.

Corte de Apelaciones de Temuco (2014): de 16 de octubre de 2014. 